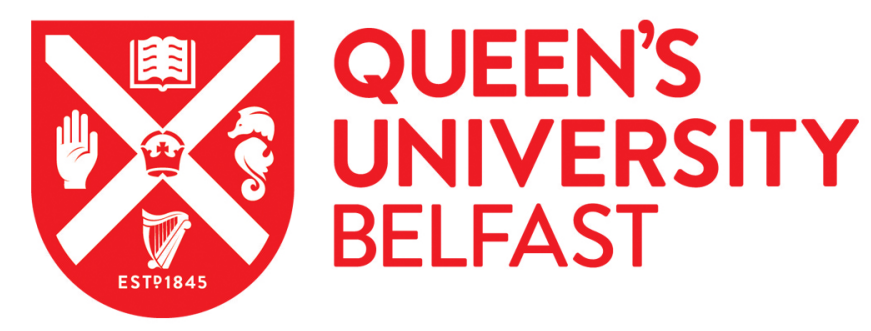

\title{
Palliative care for people with non-malignant respiratory disease and their carers: a review of the current evidence
}

McVeigh, C., Reid, J., Larkin, P., Porter, S., \& Hudson, P. (2019). Palliative care for people with non-malignant respiratory disease and their carers: a review of the current evidence. Journal of Research in Nursing. https://doi.org/10.1177/1744987119840066

Published in:

Journal of Research in Nursing

Document Version:

Peer reviewed version

Queen's University Belfast - Research Portal:

Link to publication record in Queen's University Belfast Research Portal

Publisher rights

Copyright 2018 SAGE. This work is made available online in accordance with the publisher's policies. Please refer to any applicable terms of use of the publisher.

\section{General rights}

Copyright for the publications made accessible via the Queen's University Belfast Research Portal is retained by the author(s) and / or other copyright owners and it is a condition of accessing these publications that users recognise and abide by the legal requirements associated with these rights.

Take down policy

The Research Portal is Queen's institutional repository that provides access to Queen's research output. Every effort has been made to ensure that content in the Research Portal does not infringe any person's rights, or applicable UK laws. If you discover content in the Research Portal that you believe breaches copyright or violates any law, please contact openaccess@qub.ac.uk. 
Palliative care for people with non-malignant respiratory disease and their carers: a review of the current evidence

\section{Dr Clare Mc Veigh}

School of Nursing and Midwifery, Queen's University Belfast, Belfast, Northern Ireland Dr Joanne Reid

School of Nursing and Midwifery, Queen's University Belfast, Belfast, Northern Ireland Professor Philip Larkin

School of Nursing, Midwifery and Health Systems, University College Dublin, Dublin, Ireland

\section{Professor Sam Porter}

Department of Social Sciences and Social Work, Bournemouth University, Dorset, UK

\section{Professor Peter Hudson}

Centre for Palliative Care, c/o St Vincent's University Hospital and University of Melbourne, Melbourne, Australia 


\begin{abstract}
Background: Internationally, non-malignant respiratory disease (NMRD) is on the increase. However, although palliative care is recommended as an appropriate healthcare option for this client group, evidence suggests that these patients and their carers do not receive the same standards of palliative care as patients with a malignant lung condition.
\end{abstract}

Aim: The aim of this review was to provide a critical overview of the current evidence base in relation to the palliative service provision for people with NMRD and their carers.

Methods: A review of the literature was conducted in July 2015 and updated in October 2017, focused on the palliative care service provision for patients with interstitial lung disease, COPD and bronchiectasis.

Results: Seventy-one empirical studies were included in the review and grouped in to two main themes: Patient and carer's bio-psychosocial symptom needs and management, and Palliative care service provision for patients with non-malignant respiratory disease and their carer.

Conclusion: The majority of palliative research focuses on patients with a diagnosis of COPD. A deeper insight is required into the palliative service provision experienced by those with other forms of non-malignant respiratory disease such as bronchiectasis and interstitial lung disease.

\title{
Key Words
}

Literature Review, Respiratory Disease, COPD, Bronchiectasis, Interstitial Lung Disease, Palliative Care 


\section{Introduction}

The World Health Organization (WHO) (2002) define palliative care as a holistic approach to the care of those with a life limiting illness and their carers, that relieves and prevents suffering through the early identification and assessment of physical, psychological, social and spiritual symptoms. Originally, the only patients who had access to palliative care services were those with a diagnosis of cancer and nearing the end of their life. More recently however, it has been recognised that palliative care is also applicable to patients with a nonmalignant disease, not just malignant disease (Mitchell et al. 2012), and is an integral part of a patient's disease management (O’Neill and Fallon 1997) from diagnosis.

Non- Malignant Respiratory Disease (NMRD) is an umbrella term that includes conditions such as Interstitial Lung Disease (ILD), bronchiectasis and Chronic Obstructive Pulmonary Disease (COPD) (National End of Life Care Intelligence Network 2011). Two hundred and ten million people worldwide have a diagnosis of COPD and, although the exact amount is not known, it is estimated that millions of others have other forms of chronic respiratory diseases such as ILD and bronchiectasis (WHO 2008). Non-malignant respiratory disease is a chronic, non-curable, progressive illness that requires appropriate treatment and palliative symptom management. Healthcare professionals (HCPs) provide palliative care in order to help improve the physical, psychosocial and spiritual well-being of patients with a lifelimiting illness, and their families (Mc Veigh 2016). The palliative care provided by HCPs that specialise in this area is known as specialist palliative care, and these professionals provide palliative expertise, services and resources (Faull and Blankley 2015). Generalist palliative care providers are HCPs who provide patients with palliative care however are not defined as specialists due to not having received accredited palliative care training (Gott et al. 2012). Although NMRD is on the increase internationally and nationally, evidence suggested 
that patients with NMRD and their carers do not receive the same standards of palliative care as patients with malignant respiratory disease (Goodridge et al. 2008: Partridge et al. 2009). The overall aim of this literature review was to critically discuss the current evidence base in relation to the palliative service provision for people with NMRD and their carers.

\section{Literature Review}

The search strategy within this literature review is described in Figure 1. Papers were excluded that did not meet the inclusion criteria (table 1). Empirical research papers were evaluated with guidance from the Critical Appraisal Skills Programme (CASP) critical appraisal tools (CASP UK 2012), to ensure a systematic and rigorous approach (Aveyard 2014). The CASP critical appraisal tools provided an evidence-based approach to assess the quality, quantity and consistency of the specific research designs employed by the empirical research included in the review (CASP UK). The literature was also additionally appraised by discussions with the research team. The use of themes was chosen by the researcher to appropriately identify the most commonly occurring issues in the literature (Aveyard 2010). 


\section{STAGE ONE}

\section{KEY TERMS}

- Care* OR Family OR Patient OR Healthcare Professional OR Client OR People

AND

- COPD OR Chronic Obstructive Pulmonary Disease OR Bronchiectasis OR Pulmonary Fibrosis OR Interstitial Lung Disease OR Sarcoidosis

AND

- "Palliative Care" OR "Terminal care" OR "End of Life Care" OR "Hospice Care"

\section{DATABASES SEARCHED TOGETHER}

(277 papers)

- CINAHL Plus, MEDLINE, Web of Science, Cochrane Database of Systematic Reviews, PsychINFO and PsychMed.

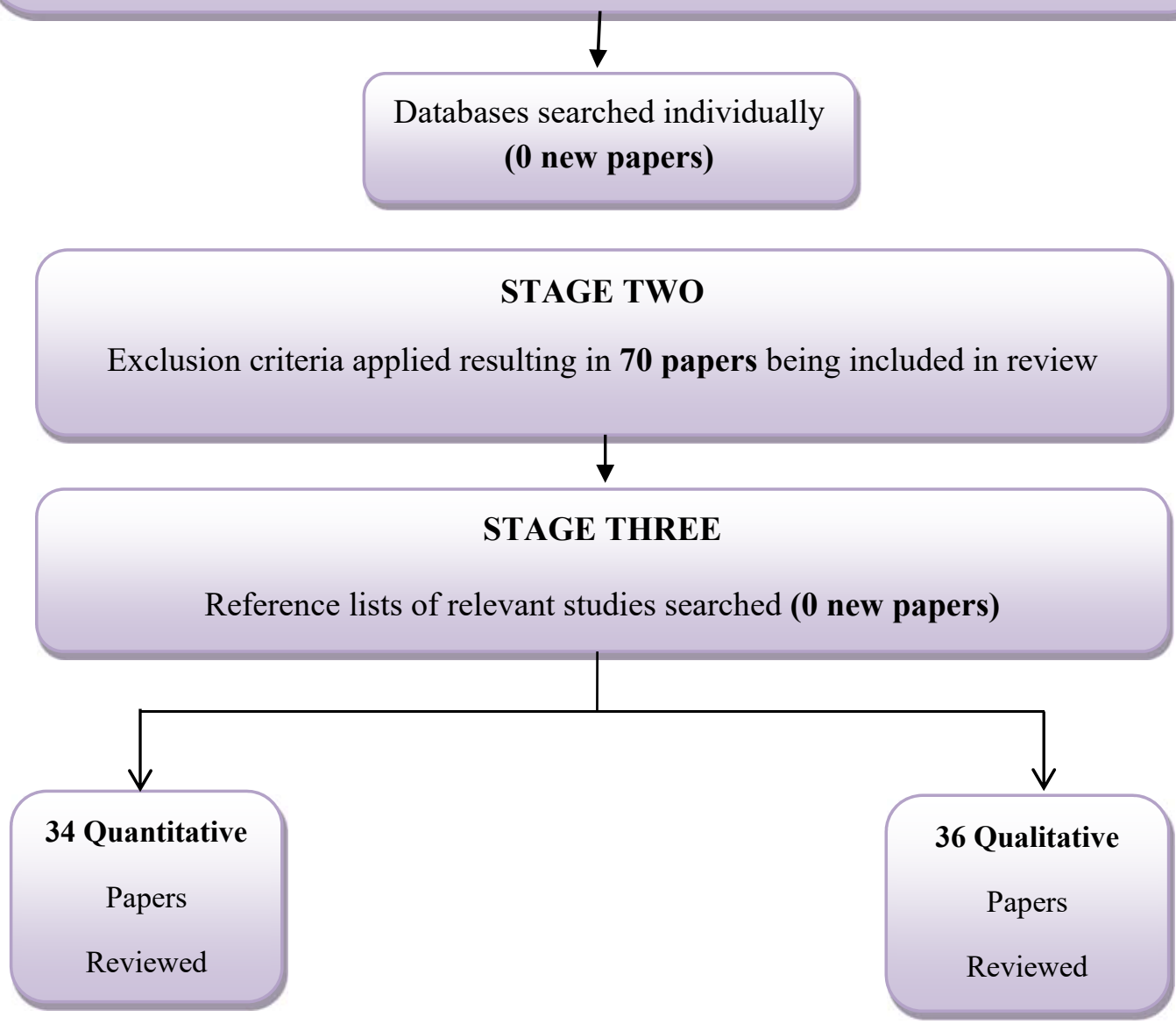


Table 1: Table outlining the inclusion criteria and exclusion

\section{INCLUSION CRITERIA}

- Papers that were written in English

- Papers that specifically referred to non-malignant respiratory disease

- Papers published no more than ten years previous to date of initial database search

- Papers that specifically referred to palliative, hospice, terminal or end of life care

\section{EXCLUSION CRITERIA}

- Papers that were not written in English

- Papers that did not specifically refer to non-malignant respiratory disease

- Papers published more than ten years previous to date of initial database search

- Papers that did not specifically refer to palliative, hospice, terminal or end of life care

In total 70 international papers informed the literature review: 34 quantitative and 36 qualitative. Each empirical paper was explored and the two themes that emerged from the literature were:: Patient and carer's bio-psychosocial symptom needs and management and Palliative care service provision for patients with NMRD and their carer.

\section{Patient and carer's bio-psychosocial symptom needs and management}

There are a number of complex symptoms associated with NMRD which can lead to reduced quality of life for these patients and their carers. Breathlessness is the symptom most commonly experienced by patients with a diagnosis of NMRD and is often the symptom found to be most distressing and severe (Ek and Ternestedt 2008: Gysels and Higginson 2008: Habraken et al. 2008: Blinderman et al. 2009: Bausewein et al. 2010: White et al. 2011: Janssen et al. 2011: Bajwah et al. 2013). For patients with advanced COPD, breathlessness can cause increased disability and impact on their quality of life (Blinderman 
et al. 2009). Gysels and Higginson (2008) argued that breathlessness can prevent patients with COPD from accessing services. Their research involved semi-structured interviews conducted with 18 patients diagnosed with moderate or severe COPD, who were experiencing problems regarding their breathlessness. Gysels and Higginson conveyed that patients had come to just adapt to their breathlessness and its restrictions as it had gradually worsened from the start of their illness. They also concluded that patients tried to hide how bad their breathlessness was as they associated it with smoking and feared that the public, and healthcare professionals (HCPs), would judge the cause of breathlessness as self-inflicted. Participants additionally expressed that they were given little advice on how to manage their symptoms and were also offered limited treatment options. Gysel and Higginson and previous research (Hasson et al. 2008: Ek and Ternestedt 2008) have emphasised the importance of a palliative care approach for patients with advanced COPD.

Breathlessness is a symptom not isolated to patients with COPD as it can also be experienced by patients with other forms of NMRD. Bajwah et al. (2013) highlighted that patients with Idiopathic Pulmonary Fibrosis (IPF), a form of ILD, also experienced severe breathlessness due to their condition. Bajwah et al. conducted 18 qualitative interviews with patients with advanced IPF, their carers and HCPs involved in their care from two specialist ILD clinics in the UK. However, previous evidence highlighted that patients with ILD experienced multiple symptoms, alongside breathlessness, that were related to their illness (Bajwah et al. 2012). Bajwah et al. previously completed a retrospective analysis of the case notes of 45 patients with IPF who had died up to 17 months previously in the UK. This study aimed to assess the palliative care symptom needs of patients with IPF, and demonstrated that $93 \%$ of participants experienced breathlessness in their last year of life, $60 \%$ experienced a cough, $29 \%$ experienced chest pain, $29 \%$ experienced fatigue and $22 \%$ experienced depression or 
anxiety. However as this study involved a retrospective chart review, caution must be taken in interpreting these results as some of the symptoms experienced by patients with IPF may not have been fully documented.

Although breathlessness is typically the main symptom associated with NMRD, patients also experience psychosocial symptoms (Janssen et al. 2011: White et al. 2011: Philip et al. 2012: Stenzel et al.2015). White et al. (2011) carried out a cross- sectional quantitative study in the UK involving 163 patients with severe COPD. Results illuminated that 35\% (95\% CI) of the participants were at a high risk of anxiety, and $43 \%(95 \% \mathrm{CI})$ were at a high risk of depression. Similarly, Janssen et al. (2011) highlighted that 28\% of participants experienced depression, alongside other as physiological symptoms. Janssen et al. carried out an observational study in Holland involving 105 outpatients with severe COPD. Results additionally demonstrated that the majority of participants were unaware of the interventions that were available to them to aid both psychological and physiological symptom management, including medication and treatment provided by HCPs.

There have been several studies that have explored the needs and experiences of carers of patients with a NMRD diagnosis (Spence et al. 2008: Hasson et al. 2009: Gysels and Higginson 2008: Hynes et al. 2012: Simpson et al. 2010: Philip et al. 2014). Caring for a patient with advanced COPD can have a physical and psychological impact on the carer (Philip et al. 2014) and they therefore require support from HCPs (Kanervisto et al. 2007). Philip et al. conducted semi-structured interviews in Australia with active $(n=9)$ and bereaved $(n=10)$ carers of patients with severe COPD. Findings demonstrated that many participants expressed that they had not chosen to be a carer. This related to the perception from 
participants that the support they provided the patient initially, had gradually developed into them having a significant caring role however there was no alternative to this role as they were the patient's sole carer. Results also indicated that the carer burden participants experienced increased as the patients illness progressed and their needs became more complex. Philip et al. also stated that many carers felt their caring role had a psychosocial impact on their health as they felt isolated and unprepared within their role, and experienced anxiety. Healthcare professionals need to recognise the bio-psychosocial needs of carers of patients with severe COPD, and be able to manage them appropriately.

Previous research has also highlighted that the palliative care needs, and symptom burden, of patients diagnosed with severe COPD (Habraken et al. 2009: Bausewein et al. 2010: Weingaertner et al. 2014: Wysham et al. 2015: Maric et al. 2016) and ILD (Matsunuma et al. 2016) may be as high as those with advanced lung cancer. Bausewein et al. conducted a cross sectional study in Germany involving 49 patients with cancer and 60 with COPD. Participants in the study completed questionnaires to measure their physical and psychological symptoms, as well as their palliative care needs. Bausewein et al. acknowledged that both groups had similarly high symptom burden and ascertained that the most prevalent symptoms in both groups were: breathlessness (42\% cancer, $58 \%$ COPD): fatigue (41\% cancer, $43 \%$ COPD): and cough (38\% cancer, $37 \%$ COPD). Although this study aimed to recruit patients from hospitals, homes and respiratory clinics, the majority of participants were from an in-patient setting. This may have affected the generalisability of the study as the perspectives of patients within the primary care setting were lacking. Additionally, patients within the acute hospital setting may have been admitted with an exacerbation of their condition and therefore may have experienced greater symptom burden. 
However, Bausewein et al. demonstrated that patients with COPD had considerable symptom burden comparable to patients with advanced cancer.

Evidence also suggested that NMRD can cause disease uncertainty amongst patients, family carers and HCPs (Gott et al. 2009: Pinnock et al. 2011: Ek et al.2015: Sampson et al. 2015). Pinnock et al. (2011) explored the perceptions of HCPs, patients and informal caregivers regarding advanced COPD. Pinnock et al. (2011 p.5) highlighted that patients with COPD conveyed a 'chaos narrative' of their disease. The patient's condition fluctuated from illness to wellness leaving them unsure of how their illness would progress. Conversely, Bajwah et al. (2012) suggested that the ILD trajectory aided patients with this form of NMRD, and their carers, to understand the life-limiting nature of their condition due to its rapid progression. Bajwah reported that as the patient's condition worsened they became aware of the lifelimiting nature of ILD. However, an all-Ireland qualitative study involving 17 bereaved carers of patients with NMRD and 18 HCPs reported that patients with ILD and their carers were often unprepared for the rapid deterioration of their condition (Mc Veigh et al. 2017a). Mc Veigh et al. illuminated that this rapid deterioration did not provide any further clarity into the life-limiting nature of the disease.

\section{Palliative care service provision for patients with NMRD and their carer}

Optimal and effective health service provision plays a key role in the delivery of effective palliative care to patients with NMRD and their carers. However research has shown that patients with NMRD, and their carers, do not always receive the palliative service provision they require (Fitzsimons et al. 2007: Goodridge et al. 2008: Gysels and Higginson 2008: Habraken et al. 2008: Hasson et al. 2008: Roberts et al. 2008: Partridge et al. 2009: Buxton 
et al. 2010: Goodridge et al. 2010: Janssen et al. 2011: Pinnock et al. 2011: Mc Veigh et al. 2017a: Mc Veigh et al. 2017b: Rush et al. 2017). Roberts et al. (2008) conducted a survey involving 100 acute NHS hospitals across the UK investigating the existing care, and quality of this care, available to patients with COPD. This survey highlighted that less than $50 \%$ of the hospitals involved had specialist palliative care services available in their area that included patients with COPD, leading to poor access to local specialist palliative care provision for this client group. This study's main limitation however, was that it sought the opinions of lead respiratory physicians who may have only provided what they perceived to be best practice.

In the UK, patients with NMRD can often have less access to specialist palliative care than those with a malignant lung disease (Partridge et al. 2009). Partridge et al. carried out a study across England, Wales and NI in which 107 respiratory physicians completed a questionnaire regarding specialist palliative care services for patients with NMRD. Findings indicated that patients with severe NMRD had less overall access to specialist palliative care services $(21.5 \%)$ than those with lung cancer. The study reported that although two-thirds of hospital inpatients, inclusive of NMRD, could easily access specialist palliative care advice, there was less accessibility related to palliative medicine out-patient services. Also, only a small number of physicians involved in the study reported easy access to hospice day or inpatient care for patients with NMRD. The study's reliability may be questioned as the validity of the questionnaire is not discussed. Also, as previously mentioned in relation to other studies, its results were based on the views of respiratory physicians alone and the study may have gained a greater insight into this phenomenon by involving other members of the multidisciplinary team. 
The geographical area a patient diagnosed with NMRD lives in can also influence the level of palliative care service provision they receive (Goodridge et al. 2010). Goodridge et al. (2010) undertook a cohort study retrospectively investigating the healthcare data of 1098 patients who died of a respiratory illness in Canada. This was a novel study as it aimed to examine the rural-urban differences in healthcare utilisation, or location of death for patients who died of COPD or lung cancer. Results conveyed that patients in their last year of life living in rural areas were less likely to receive physician visits and home care services than those in urban areas. However, this study did not investigate the reasons for the differences in the palliative care provided in rural and urban areas. Palliative care provision for NMRD in rural and urban areas needs to be further explored, and future research should not only take into account the patients and carers perspective but also the views of HCPs regarding the delivery of generalist and specialist palliative care to these patients. This will help to provide an insight into what are the barriers and facilitators associated with providing care to patients with NMRD in rural and urban areas.

Higginson et al. (2014) conducted a randomised controlled trial (RCT) in the UK assessing the effectiveness of integrating specialist palliative care early for patients with advanced disease. Fifty- four percent of participants had a diagnosis of COPD $(n=57), 20 \%$ cancer $(n=21), 18 \%$ ILD $(n=19), 5 \%$ heart failure $(n=5)$ and $3 \%$ had another form of advanced disease $(n-=3)$. The involvement of specialist palliative care early in the disease trajectory of patients with ILD can help manage their physiological and psychosocial symptoms (Higginson et al. ). This RCT demonstrated that patients with ILD and COPD who received early specialist palliative care involvement experienced alleviated breathlessness and 
increased short term survival: $100 \%(\mathrm{n}=29)$ vs. $79 \%(\mathrm{n}=22)$ for COPD, and $100 \%(\mathrm{n}=7)$ vs. $67 \%(\mathrm{n}=8)$ for ILD at 180 days post commencement of the study. Further investigation with this population is required however to illuminate the effects of early specialist palliative care on long term survival, findings that have previously been identified in patients with lung cancer (Temel et al. 2010). Although previous research has recommended the involvement of specialist palliative care for patients with ILD (Bajwah et al. 2012: Bajwah et al. 2013: Higginson et al. 2014), referrals to specialist care are often low for this patient group(Bajwah et al. 2013: Lindell et al. 2015: Mc Veigh et al. 2017). Mc Veigh et al. illuminated that this is often attributed to HCPs lack of awareness of the role of palliative care for this client group.

Some research has provided evidence of ways in which optimal palliative care service provision can be provided to patients with NMRD (Janssen et al. 2010: Farquhar et al. 2016: Mc Veigh et al. 2017b). Janssen et al. provided details of three case studies of patients diagnosed with COPD or ILD who were part of a patient centred interdisciplinary palliative care program specifically for patients with end-stage NMRD in the Netherlands. The programme involved the daily management of patients' symptoms by a team consisting of both specialist and generalist palliative care providers. Janssen et al. argued that results demonstrated how a palliative care program may have helped to improve the patient's quality of life, reduced their need for hospital admissions and supported patients with NMRD in achieving a better quality of death through the appropriate management of symptoms such as breathlessness. However this research was not inclusion of all forms of NMRD. Mc Veigh et al. (2017b) highlighted a potential model of palliative care for patients with NMRD, inclusive of bronchiectasis. The potential model was derived from the findings of qualitative interviews with bereaved carers of patients with NMRDs, and focus group with HCPs. This model proposed three levels of holistic care for this client group, highlighting the importance of the 
involvement of generalist palliative care and specialist respiratory care providers in the care of patients with NMRD from diagnosis. It additionally proposed that the need for specialist palliative care involvement should be assessed throughout the illness trajectory, and involved based on symptom complexity. However, Janssen et al. and Mc Veigh et al. argued the need for further interventional research to explore the implementation of these models of palliative care in clinical practice.

\section{Conclusions}

Evidence suggested disparities in the provision of specialist and generalist palliative care to patients with NMRD, in comparison to those with a malignant diagnosis. This review of the literature has highlighted that there are several gaps in the current research involving the palliative care provided to patients with NMRD. Further research is required to provide a deeper insight into the palliative care provision experienced by those diagnosed with ILD and Bronchiectasis alongside COPD, as the majority of research investigates COPD alone.

\section{Key Points}

- Evidence suggested that patients with NMRD and their carers do not receive the same standards of palliative care as patients with malignant respiratory disease.

- Family caregivers also require holistic care.

- There is a lack of evidence regarding palliative care for ILD and bronchiectasis.

- Future policy needs to acknowledge the role of palliative care for patients with all forms of NMRD, and their carers, and ensure optimal implementation in clinical practice. 


\section{Ethical Permissions}

Ethical permissions were not required as this review did not include primary data collection.

\section{References}

Bajwah, S., Koffman, J. Higginson, I. J., Ross, J. R., Wells, A. U., Birring, S. S. and Riley, J. (2012) " "I wish I knew more..." the end-of-life planning and information needs for end-stage fibrotic interstitial lung disease: views of patients, carers and health professionals.' $B M J$ supportive \& palliative care. 3 (1), p.p. 84-90.

Bajwah, S., Higginson, I. J., Ross, J. R., Wells, A. U., Birring, S. S., Patel, A. and Riley, J. (2012) 'Specialist palliative care is More Than Drugs: A retrospective Study of ILD Patients.' Lung. 190 (2), p.p. 215-220.

Bajwah, S., Higginson, I. J., Ross, J. R., Wells, A. U., Birring, S. S., Riley, J., and Koffman, J. (2013) 'The palliative care needs for fibrotic interstitial lung disease: a qualitative study of patients, informal carers and health professionals.' Palliative medicine, 27(9), p.p. 869-876.

Bausewein, C., Booth, S., Gysels, M., Kuhnbach, R., Haberland, B. And Higginson, I. J. (2010) 'Understanding Breathlessness: Cross- Sectional Comparison of Symptom Burden and Palliative Care Needs in Chronic Obstructive Pulmonary Disease and Cancer.' Journal of Palliative Medicine. 13 (9), p.p. 1109- 1118.

Blinderman, C. D., Homel, P., Billings, J. A., Tennstedt, S. and Portenoy, R. K. (2009) 'Symptom distress and quality of life in patients with advanced chronic obstructive pulmonary disease.' Journal of pain and symptom management, 38 (1), p.p. 115-123.

Buxton, K. L., Stone, R. A., Buckingham, R. J., Pursey, N. A. and Roberts, C. M. (2010) 'Current and planned palliative care service provision for chronic obstructive pulmonary disease patients in 239 UK hospital units: comparison with the gold standards framework.' Palliative Medicine, 24 (5), p.p. 480- 485.

CASP UK (2012) CASP Checklists. (Accessed 22 September 2017). Available at: http://www.casp-uk.net/\#!casp-tools-checklists/c18f8

Ek, K., Andershed, B., Sahlberg-Blom, E. and Ternestedt, B.M., 2015. "The unpredictable death"-The last year of life for patients with advanced COPD: Relatives' stories. Palliative \& supportive care, 13(5), pp.1213-1222.

Ek, K. and Ternestedt, B. M. (2008) 'Living with chronic obstructive pulmonary disease at the end of life: a phenomenological study.' Journal of Advanced Nursing. 64 (4), p.p. 470478. 
Farquhar, M.C., Prevost, A.T., McCrone, P., Brafman-Price, B., Bentley, A., Higginson, I.J., Todd, C.J. and Booth, S. (2016). The clinical and cost effectiveness of a Breathlessness Intervention Service for patients with advanced non-malignant disease and their informal carers: mixed findings of a mixed method randomised controlled trial. Trials, 17(1), p.185.

Faull, C. and Blankley, K. (2015). Palliative Care. $2^{\text {nd }}$ Edition. UK: Oxford University Press.

Fitzsimons, D., Mullan, D., Wilson, J. S., Conway, B., Corcoran, B., Dempster, M., Gamble, J., Stewart, C., Rafferty, S., Mc Mahon, M., Mac Mahon, J., Mullholland, P., Stockdale, P., Chew, E., Hanna, L., Brown, J., Ferguson, G. and Fogarty, D. (2007) 'The challenge of patients' unmet needs in the final stages of chronic illness.' Palliative Medicine. 21, p.p. 313322.

Goodridge, D., Lawson, J., Duggleby, W., Marciniuk, D., Rennie, D. and Stang, M. (2008) 'Health care utilization of patients with chronic obstructive pulmonary disease and lung cancer in the last 12 months of life.' Respiratory Medicine. 102 (6), p.p. 885- 891

Goodridge, D., Lawson, J., Rennie, D. and Marciniuk, D. (2010) 'Rural/Urban differences in health care utilization and place of death for persons with respiratory illness in the last year of life.' Rural and Remote Health. 10 (1349), p.p. 1-15.

Gott, M. C., Gardiner, N. S., Payne, S., Seamark, D., Barnes, S., Halpin, D. and Ruse, C. (2009) 'Barriers to advance care planning in chronic obstructive pulmonary disease.' Palliative Medicine. 23 (7), p.p. 642-648.

Gott, M., Seymour, J., Ingleton, C., Gardiner, C. and Bellamy, G. (2012) 'That's part of everybody's job': the perspectives of health care staff in England and New Zealand on the meaning and remit of palliative care.' Palliative Medicine. 26 (3), p.p. 232-241.

Gysels, M. and Higginson, I. J. (2008) 'Access to Services for Patients with Chronic Obstructive Pulmonary Disease: The Invisibility of Breathlessness.' Journal of Pain and Symptom Management. 36 (5), p.p. 451- 460.

Habraken, J. M., Pols, J., Bindels, P. J. E. And Willems, D. L. (2008) 'The silence of patients with end-stage COPD: a qualitative study.' British Journal of General Practice. 58, p.p. 844849.

Hasson, F., Spence, A., Waldron, M., Kernohan, G., Mc Laughlin, D., Watson, B. and Cochrane, B. (2008) 'I cannot get a breath: experiences of living with advanced chronic obstructive disease.' International journal of Palliative Nursing. 14 (11), p.p.526- 531. 
Hasson, F., Spence, A., Waldron, M., Kernohan, G., Mc Laughlin, D., Watson, B. and Cochrane, B. (2009) 'Experiences and Needs of Bereaved Carers during Palliative and Endof- Life Care for People with Chronic Obstructive Pulmonary Disease.' Journal of Palliative Care. 25 (3), p.p. 157- 163.

Higginson, I. J., Bausewein, C., Reilly, C. C., Gao, W., Gysels, M., Dzingina, M., and Moxham, J. (2014) 'An integrated palliative and respiratory care service for patients with advanced disease and refractory breathlessness: a randomised controlled trial.' The Lancet Respiratory Medicine. 2 (12), p.p. 979- 987.

Hynes, G., Stokes, A., and McCarron, M. (2012) 'Informal care-giving in advanced chronic obstructive pulmonary disease: lay knowledge and experience.' Journal of clinical nursing. 21 (7-8), p.p. 1068-1077.

Janssen, D. J. A., Spruit, M. A., Alsemgeest, T. P. G., Does, J. D., Schols, J. M. G. A. and Wouters, E. F. M. (2010) 'A patient-centred interdisciplinary palliative care programme for end-stage chronic respiratory diseases.' International Journal of Palliative Nursing. 16 (4), p.p. 189- 194.

Janssen, D. J. A., Curtis, J. R., Au, D. H., Spruit, M. A., Downey, L., Schols, J. M. G. A., Wouters, E. F. M. and Engelberg, R. A. (2011) 'Patient-clinician communication about endof-life care for Dutch and US patients.' European Respiratory Journal. 38 (2), p.p. 268-276.

Kanervisto, M., Kaistila, T. And Paavilainen, E. (2007) 'Severe chronic obstructive pulmonary disease in a family's everyday life in Finland: Perceptions of people with chronic obstructive pulmonary disease and their spouses.' Nursing and Health Sciences. 9, p.p. 40-47.

Lindell, K. O., Liang, Z., Hoffman, L. A., Rosenzweig, M. Q., Saul, M. I., Pilewski, J. M., Gibson, K. F. and Kaminski, N. (2015) 'Palliative Care and Location of Death in Decedents with Idiopathic Pulmonary Fibrosis.' Chest. 147 (2), p.p. 423-429.

Maric, D., Jovanovic, D., Nagorni-Obradovic, L., Stjepanovic, M., Kisic-Tepavcevic, D. and Pekmezovic, T., 2016. Assessment of health-related quality of life in end-stage chronic obstructive pulmonary disease and non-small-cell lung cancer patients in Serbia. Palliative \& supportive care, 14(1), pp.60-68.

Matsunuma, R., Takato, H., Takeda, Y., Watanabe, S., Waseda, Y., Murakami, S., Kawaura, Y. and Kasahara, K., 2016. Patients with end-stage interstitial lung disease may have more problems with dyspnea than end-stage lung cancer patients. Indian journal of palliative care, 22(3), p.282.

Mc Veigh, C., Reid, J., Larkin, P., Porter, S. and Hudson, P., (2017a). The experience of palliative care service provision for people with non-malignant respiratory disease and their family carers: an all-Ireland qualitative study. Journal of Advanced Nursing. 
Mc Veigh, C., Reid, J., Larkin, P., Porter, S. and Hudson, P., (2017b). The provision of generalist and specialist palliative care for patients with non-malignant respiratory disease in the North and Republic of Ireland: a qualitative study. BMC palliative care, 17(1), p.6.

Mc Veigh, C. (2016) Chapter 27: Palliative Care approaches to Chronic Obstructive Airways Disease. In: Ingleton, C. and Larkin, P. (2016) Palliative Care nursing- at a Glance. UK: Wiley.

Mitchell, H., Noble, S., Finlay, I. and Nelson, A. (2012) 'Defining the palliative care patient: its challenges and implications for service delivery.' BMJ supportive and palliative care. 3 , p.p. $46-52$.

National End of Life Care Intelligence Network (2011) Deaths from Respiratory Diseases: Implications for End of Life Care in England. Bristol: National End of Life Care Intelligence Network.

O' Neill, B. and Fallon, M. (1997) 'ABC of Palliative Care: Principles of Palliative Care and Pain Control.’ British Medical Journal. 315, p.p. 801-804.

Partridge, M. R., Khatri, A., Sutton, L., Welham, S. and Afmedzai, S. H. (2009) 'Palliative care services for those with chronic lung disease.' Chronic Respiratory Disease. 6, p.p. 1317.

Paterson, B. L., Thorne, S. E., Canam, C., and Jillings, C. (2001). Meta-study of qualitative health research: A practical guide to meta-analysis and meta-synthesis. Thousand Oaks, CA: Sage.

Philip, J., Gold, M., Brand, C., Douglass, J., Miller, B., and Sundararajan, V. (2012) 'Negotiating hope with chronic obstructive pulmonary disease patients: a qualitative study of patients and HCPs.' Internal Medicine Journal. 42 (7), p.p. 816-822.

Philip, J., Gold, M., Brand, C., Miller, B., Douglass, J. and Sundararajan, V. (2014) 'Facilitating Change and Adaptation: The Experiences of Current and Bereaved Carers of Patients with Severe Chronic Obstructive Pulmonary Disease.' Journal of palliative medicine. 17 (4), p.p. 421-427.

Pinnock, H., Kendall, M., Murray, S. A., Worth, A., Porter, M., Mac Nee, W. and Sheikh, A. (2011) 'Living and dying with severe chronic obstructive pulmonary disease: multiperspective longitudinal qualitative study.’ British Medical Journal. 342 (d142), p.p. 1- 10.

Roberts, C. M., Seiger, A., Buckingham, R. J. and Stone, R. A. (2008) 'Clinician perceived good practice in end- of- life care for patients with COPD.' Palliative Medicine. 22, p.p. 855858. 
Rush, B., Hertz, P., Bond, A., McDermid, R.C. and Celi, L.A., 2017. Use of palliative care in patients with end-stage COPD and Receiving home oxygen: national trends and barriers to care in the United States. CHEST Journal, 151(1), pp.41-46.

Sampson, C., Gill, B.H., Harrison, N.K., Nelson, A. and Byrne, A., 2015. The care needs of patients with idiopathic pulmonary fibrosis and their carers (CaNoPy): results of a qualitative study. BMC pulmonary medicine, 15(1), p.155.

Simpson, A. C., Young, J., Donahue, M., and Rocker, G. (2010) 'A day at a time: caregiving on the edge in advanced COPD.' International journal of chronic obstructive pulmonary disease. 5, p.p. 141-151.

Spence, A., Hasson, F., Waldron, M., Kernohan, G., McLaughlin, D., Cochrane, B., and Watson, B. (2008) 'Active carers: living with chronic obstructive pulmonary disease in the family.' International journal of palliative nursing, 14(8), p.p. 368-372.

Stenzel, N.M., Vaske, I., Kühl, K., Kenn, K. and Rief, W., 2015. Prediction of end-of-life fears in COPD-hoping for the best but preparing for the worst. Psychology \& health, 30(9), pp.1017-1034.

Weingaertner, V., Scheve, C., Gerdes, V., Schwarz-Eywill, M., Prenzel, R., Bausewein, C., Higginson, I. J., Voltz, R., Herich, L. and Simon, S. T. (2014) 'Breathlessness, Functional Status, Distress, and Palliative Care Needs Over Time in Patients With Advanced Chronic Obstructive Pulmonary Disease or Lung Cancer: A Cohort Study.' Journal of pain and symptom management. 48 (4), p.p. 569-581.

White, P., White, S., Edmonds, P., Gysels, M., Moxham, J., Seed, P. and Shipman, C. (2011) 'Palliative care or end- of- life care in advanced chronic obstructive pulmonary disease. A prospective community survey.' The British Journal of General Practice. 61 (587), p.p. 362370.

World Health Organisation (WHO) (2002) The WHO Definition of Palliative Care. Available at: http://www.who.int/cancer/palliative/definition/en/ (Accessed: 20/10/2017).

World Health Organisation (WHO) (2008) Global Alliance against Chronic Respiratory Disease Action Plan 2008-2013. Italy: WHO.

Wysham, N.G., Cox, C.E., Wolf, S.P. and Kamal, A.H., 2015. Symptom burden of chronic lung disease compared with lung cancer at time of referral for palliative care consultation. Annals of the American Thoracic Society, 12(9), pp.1294-1301. 